\title{
Non-face-to-face treatment of stress urinary incontinence: predictors of success after 1 year
}

\author{
Anna Lindh $^{1,2}$ - Malin Sjöström ${ }^{2}$ - Hans Stenlund ${ }^{1}$ - Eva Samuelsson ${ }^{1}$
}

Received: 3 January 2016 / Accepted: 10 May 2016 / Published online: 3 June 2016

(C) The Author(s) 2016. This article is published with open access at Springerlink.com

\begin{abstract}
Introduction and hypothesis The objective was to determine predictors of long-term success in women with stress urinary incontinence (SUI) treated with a 3-month pelvic floor muscle training (PFMT) program delivered via the Internet or a brochure.

Methods We included 169 women with SUI $\geq 1$ time/week who completed the 1-year follow-up $(n=169$, mean age 50.3, SD 10.1 years). Three outcome variables defined success after 1 year: Patient Global Impression of Improvement (PGI-I), International Consultation on Incontinence Modular Questionnaire Urinary Incontinence Short Form (ICIQ-UI $\mathrm{SF}$ ), and sufficient treatment. Using logistic regression, we analyzed data from the baseline, and from the 4-month and 1 -year follow-ups, for potential predictors of success.

Results Of the participants, $77 \%$ (129 out of 169) were successful in $\geq 1$ of the outcomes, $23 \%$ (37 out of 160) were successful in all 3. Participants with successful short-term results were more likely to succeed in the corresponding outcome at 1 year than those without successful short-term results (adjusted odds ratios [ORs]: PGI 5.15, $95 \%$ confidence interval [CI] 2.40-11.03), ICIQ-UI SF 6.85 (95\% CI 2.83-16.58), and sufficient treatment 3.78 (95\% CI 1.58-9.08). Increasing age predicted success in PGI-I and sufficient treatment (adjusted OR 1.06, 95 \% CI 1.02-1.10, and 1.08, 95 \% CI, $1.03-$
\end{abstract}

Anna Lindh

anna.lindh@regionjh.se

1 Department of Public Health and Clinical Medicine, Umeå University, Umeå, Sweden

2 Department of Public Health and Clinical Medicine, Unit for Research, Education and Development - Östersund, Umeå University, Umeå, Sweden
1.13 respectively). Compared with not training regularly, regular PFMT at 1 year predicted success for PGI and sufficient treatment (adjusted OR 2.32, $95 \%$ CI 1.04-5.20, and 2.99, $95 \%$ CI 1.23-7.27 respectively).

Conclusion The long-term success of a non-face-to-face treatment program for SUI with a focus on PFMT can be predicted by successful short-term results, increasing age, and the performance of regular PFMT after 1 year.

Keywords eHealth $\cdot$ Long-term $\cdot$ Pelvic floor muscle training $\cdot$ Predictors $\cdot$ Self-management $\cdot$ Stress urinary incontinence

\section{Introduction}

The most common form of incontinence in women is stress urinary incontinence (SUI), affecting 10-35\% of women [1]. Symptoms of SUI are leakage during exertion, coughing, or sneezing [2], and diagnosis before starting non-surgical treatment in an outpatient setting can be based on the symptoms reported by the patient $[3,4]$. High BMI, older age, smoking, parity, vaginal delivery, and weakening of the pelvic floor are some of the known risk factors for the development of SUI [5, 6]. The first treatment of choice is pelvic floor muscle training (PFMT) combined with lifestyle interventions, such as weight loss if the person is overweight [7, 8]. The majority of women with SUI report an improvement after 3 months of PFMT [3, 9] and 1 in 3 women becomes continent [4]. The long-term success of PFMT varies between 41 and $85 \%$ [10].

Several studies have investigated the predictors of shortterm results after PFMT, but the results have been contradictory. Suggested predictors of a positive result at 3 months are menopause, higher education, no previous urinary incontinence surgery [11], poor contraction strength at baseline, 
and great improvement in pelvic floor muscle strength [12]. There is limited knowledge on the predictors of long-term outcome, which could be useful for both patients and clinicians for predicting in whom PFMT will be successful and who will need surgery.

In a recent randomized controlled trial (RCT), women with SUI treated with non-face-to face treatment focusing on PFMT were significantly improved at the 4-month follow-up. The improvements were maintained at the 1-year and 2-year followups $[13,14]$. The aim of the present study was to evaluate clinically relevant predictors of long-term success after nonface-to-face treatment focusing on PFMT in women with SUI.

\section{Materials and methods}

\section{Study population}

The analyses in this study are based on data from an RCT conducted between 2009 and 2011 (ID: NCT01032265). Women were enrolled in the project via an online screening survey that evaluated the type of incontinence and inclusion and exclusion criteria. The inclusion criteria were: female, age 18-70 years, SUI $\geq 1$ time/week, ability to read and write Swedish, and access to a computer with the Internet. The exclusion criteria were: leakage associated with urgency, previous UI surgery, pregnancy, known malignancy in the lower abdomen, difficulties passing urine, macroscopic hematuria, intermenstrual bleeding, severe psychiatric disorders or Hospital Anxiety and Depression Scale (HADS) score $>15$ for depression or anxiety, and neurological disease affecting sensitivity in the legs or lower abdomen. Women considered eligible were sent self-assessment questionnaires for additional evaluation, including the validated questionnaires, the Lower Urinary Tract Symptoms Quality of Life (ICIQLUTSqol) and the International Consultation on Incontinence Modular Questionnaire Urinary Incontinence Short Form (ICIQ-UI SF), medical history, and a 2-day bladder diary. After their completion, a telephone interview was performed by a urotherapist to confirm the diagnosis of SUI. A total of 250 women aged $18-70$ years with SUI $\geq 1$ time/ week were randomized by computer-generated block randomization to either an Internet-based training program or a program delivered by post to compare the effect of the two programs after a 3-month treatment period. The programs consisted of PFMT of increasing intensity three times per day for 3 months including contractions for strength and endurance, quick contractions, and the "knack maneuver" with information and lifestyle advice. No face-to-face education was provided before or during the PFMT program. Followup was performed at 4 months and 1 year using self-assessed questionnaires. The RCT was described in detail by Sjöström et al. [13].
All women who answered the 1-year follow-up questionnaires were included in the present study $(n=169)$. Participants in both groups achieved highly significant and clinically relevant improvements in the primary outcomes symptom severity and condition-specific quality of life, and the groups did not significantly differ in these measures [13]. In the present study, the analyses include all participants regardless of treatment group. At 1 year, $3 \%$ of the women (5 out of 169,3 from the postal group and 2 from the Internet group) had undergone surgery for SUI and were also included in the study. None of the women received new medications for incontinence during the study period.

\section{Definition of success}

We used three outcomes to define success after 1 year:

1. Patient Global Impression of Improvement (PGI-I), a validated [15], patient-reported evaluation of the result of treatment consisting of one question: "How is your urinary leakage now compared with before treatment?" On a scale with seven alternatives ranging from very much worse to very much better, participants answering that they were much better or very much better were considered to have a successful outcome.

2. The ICIQ-UI SF is a validated and highly recommended symptom scoring instrument $[3,8,16]$ that evaluates symptoms such as frequency, amount of leakage, and overall inconvenience. It consists of four questions: three adding up to a score (0-21 points) and the fourth used to determine the type of incontinence. The minimal important difference (MID) in improvement is the difference between the ICIQ-UI SF score at inclusion and at follow-up. An overall score reduction of 2.5 can be considered clinically relevant [17]. We used $\geq 3$ (rounded up to the closest integer) to define success.

3. "Sufficient treatment" is a question from the follow-up questionnaire: "Do you currently think that the treatment you underwent is sufficient?" answered with "No," "Yes, I am completely cured from my urinary leakage," or "Yes, I think the treatment is sufficient even though I am not completely cured." We considered the two answer alternatives beginning with "yes" as a successful outcome.

\section{Possible predictors}

The possible predictors of long-term success we chose to analyze included known risk factors for SUI [5-7] and suggested predictors from short-term results $[11,12,18-20]$. Because short-term success likely affects long-term success, we included data from the 4-month follow-up [10]. We also included the amount of PFMT performed after 1 year. The data at baseline 
consisted of age, body mass index $\left(\mathrm{kg} / \mathrm{m}^{2}\right)$, education, menopausal status, parity, vaginal delivery of a child $\geq 4,000 \mathrm{~g}$, local estrogen use, physical activity, time since onset of SUI, previously sought medical contact for SUI, ICIQ-UI SF, conditionspecific quality of life as measured by the questionnaire ICIQLUTSqol, tea drinking, motivation to perform PFMT (Likert scale 1-10), and self-rated ability to perform PFMT (Likert scale 1-10). The data from the 4-month follow-up consisted of PGI-I, MID ICIQ-UI SF, sufficient treatment, and MID ICIQLUTSqol. The data from the 1-year follow-up concerned how often PFMT had been performed in the last 3 months, which could be answered with "Never," "Sporadically, less than once a week," "Regularly, 1-3 times/week," "Regularly, more than 3 times/week," or "Regularly, daily."

\section{Statistical analysis}

The baseline variables ICIQ-UI SF, ICIQ-LUTSqol, and age were treated as continuous variables and the other possible predictors as categorical variables. At the 4-month followup, the possible predictors PGI-I, ICIQ-UISF, and sufficient treatment were analyzed in the same way as at the 1-year follow-up. The ICIQ-LUTSqol was divided into two categories based on the score reduction between inclusion and the 4month follow-up; a score reduction exceeding the established MID (i.e., 24) [17] was considered a relevant improvement. The categorical variables were divided into categories on the original questionnaire. To have enough participants in each category to proceed with analyses, we had to create fewer categories by adding them together. The categories were reduced based on clinical relevance and the distribution of answers for the following predictors: body mass index $\left(\mathrm{kg} / \mathrm{m}^{2}\right)$, education, physical activity, time since onset of SUI, tea drinking, motivation to perform PFMT, self-rated ability to perform PFMT, and how often PFMT had been performed in the last 3 months at the 1-year follow-up. PFMT at 1 year was changed into two categories in which the answers beginning with "regularly" were in one category and "never" or "sporadically, less than one time/week" were another category, as shown in Table 2.

The outcome variables were recoded as 1 for success and 0 for failure. The relationships between each of the potential predictors and the outcomes were tested using the Chisquared test for categorical variables, independent $t$ test for continuous variables, and univariate logistic regression. Age and predictors with $p<0.25$ were used in a final multivariate model in which non-significant $(p>0.05)$ predictors were manually removed one-by-one starting with the predictor with the highest $p$ value, leaving only predictors with $p<0.05$. The multivariate analysis was also performed without the five women who had undergone surgery.

All statistical analyses were performed using SPSS version 22.0 software.

\section{Ethics}

The study was ethically approved by the Regional Ethical Review Board, Umeå University (number 08-124 M and 2015-79-32 M).

\section{Results}

Of the 169 women included, 1 did not answer the PGI-I, 3 did not complete the ICIQ-UI SF, and 7 did not answer the question about sufficient treatment. The baseline data are summarized in Table 1 . The mean age was 50.3 years, less than onethird of patients were overweight or obese, and most women were highly educated. The mean ICIQ-UI SF score was 10.1, which corresponds to moderate severity [21].

Table 1 Baseline characteristics of participants who completed 1-year follow-up $(n=169)$

\begin{tabular}{ll}
\hline Characteristic & Data \\
\hline Mean age, years (SD) & $50.3( \pm 10.1)$ \\
BMI, $n(\%)$ & \\
$<25$ & $117(69.2)$ \\
$25-30$ & $37(21.9)$ \\
$>30$ & $15(8.9)$ \\
Education, $n(\%)$ & \\
Primary and secondary & $41(24.3)$ \\
Post-secondary & $128(75.7)$ \\
Parity, mean (SD) & $2.07( \pm 0.99)$ \\
Vaginal delivery of child weighing >4,000 g, $n(\%)$ & $49(29.0)$ \\
Use of local estrogen, $n(\%)$ & $22(13.0)$ \\
Premenopausal, $n(\%)$ & $94(55.6)$ \\
Moderate physical activity, $n(\%)$ & \\
$<3$ h/week & $58(34.3)$ \\
3-5 h/week & $54(32.0)$ \\
$>5$ h/week & $57(33.7)$ \\
Duration of SUI, $n(\%)$ & \\
$<1$ year & $9(5.3)$ \\
1-5 years & $70(41.4)$ \\
$>5$ years & $90(53.3)$ \\
ICIQ-UI SF, mean (SD) & $10.14( \pm 3.20)$ \\
UsiQ-LUTSqol, mean $(\mathrm{SD})$ & $32.70( \pm 6.78)$ \\
\hline
\end{tabular}

$S D$ standard deviation, $n$ number of observations, $S U I$ stress urinary incontinence, $B M I$ body mass index $\left(\mathrm{kg} / \mathrm{m}^{2}\right), I C I Q-U I S F$ International Consultation on Incontinence Modular Questionnaire Urinary Incontinence Short Form, ICIQ-LUTSqol International Consultation on Incontinence Modular Questionnaire Lower Urinary Tract Symptoms quality of life 


\section{Proportion of successful results after 1 year}

Among the study participants, $77 \%$ (129 out of 169) were successful in at least one of the outcome variables. The outcome variables corresponded to the following success rates: PGI-I, $33 \%$ (55 out of 168); ICIQ-UI SF, $57 \%$ (95 out of 166); and sufficient treatment, $57 \%$ (93 out of 162). Twentythree percent of the women (37 out of 160) were successful in all three outcome variables (Fig. 1).

Of the women who were successful at the 4-month followup, 55-76\% were still successful in the corresponding outcome at 1 year. However, $20-31 \%$ of the women who failed at the 4-month follow-up succeeded at the 1-year follow-up (Fig. 2).

\section{Predictors of a successful outcome after 1 year}

The possible predictors time since debut of SUI, previously sought medical contact for SUI, education, and BMI did not result in a p-value $<0.25$ in any of the outcome variables and were not included in the multivariate analysis. The remainder of the potential predictors had p-values $<0.25$ in one or more of the outcome variables in the univariate analysis and are presented in Table 2.

In the final multivariate regression models (Table 3), a successful result at 4 months for each of the outcome variables predicted a successful result at 1 year for the same outcome variable. Increasing age and performance of regular PFMT during the last 3 months before the 1-year follow-up remained significant predictors in two of the outcome variables.
Physical activity had inconsistent results, and there was a trend toward better results with less physical activity in the outcome PGI-I, but the trend was lacking in the outcome ICIQ-UI SF. The severity defined by ICIQ-UI SF at baseline had contradictory results; increased severity at baseline predicted success in the outcome ICIQ-UI SF and less severe leakage at baseline predicted success in the outcome sufficient treatment. The self-rated ability to perform PFMT remained a significant predictor of a successful outcome in one outcome variable.

The results from the multivariate analysis did not change when the 5 women who had undergone surgery by 1 year were removed from the analysis.

\section{Discussion}

The main predictors of long-term success after non-face-toface treatment based on PFMT in women with SUI were a successful result at 4 months, the performance of regular PFMT after 1 year, and increasing age. The severity of incontinence at baseline and physical activity had inconsistent results, and the self-rated ability to perform PFMT was only significant in one of the outcome variables.

\section{Strengths}

The population in this study was well defined, as all women had clinically relevant SUI with $\geq 1$ leakage/week and actively sought treatment. PFMT is the first choice for the treatment of
Fig. 1 Proportion of patients with successful outcomes in the variables "PGI-I," "ICIQ-UI SF," and "sufficient treatment" at 1 year. PGI-I Patient Global Impression of Improvement, ICIQ-UI SF International Consultation on Incontinence Modular Questionnaire Urinary Incontinence Short Form

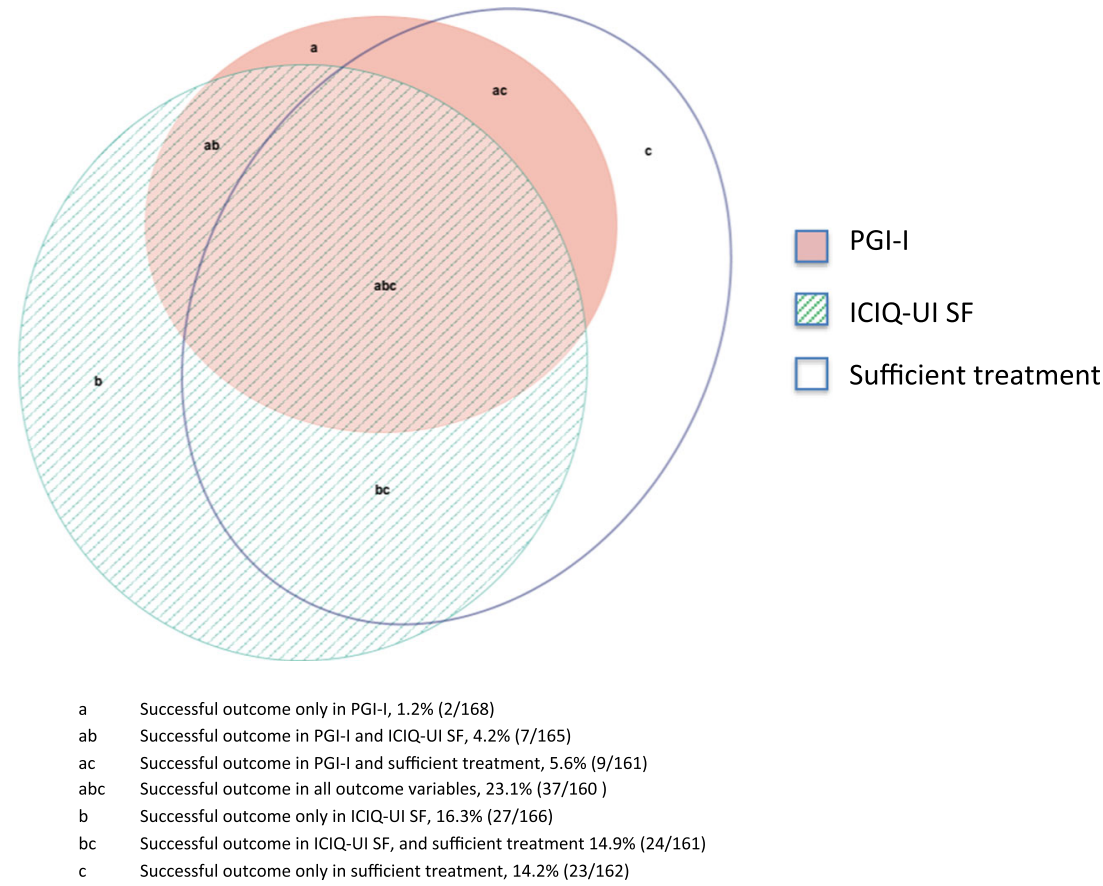



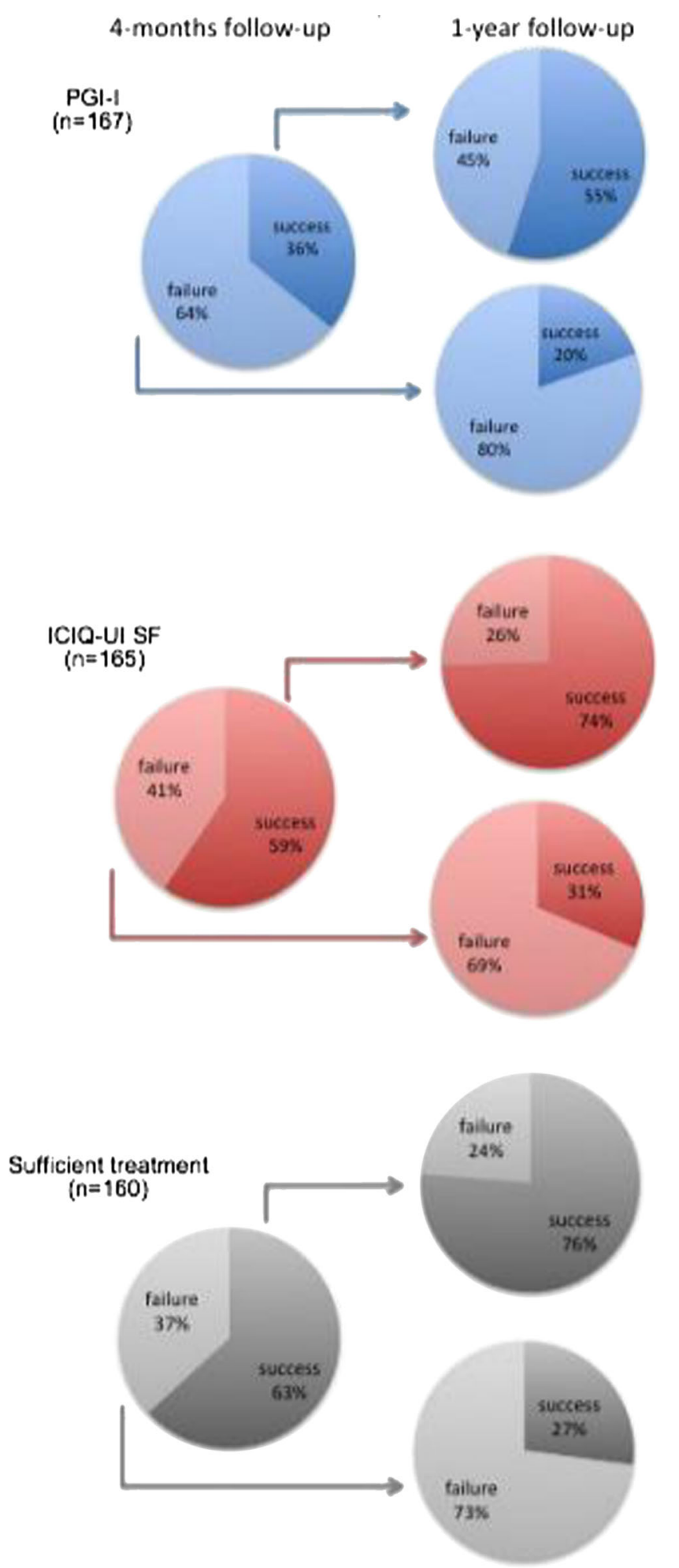

Fig. 2 Proportion of participants with success and failure at 4 months and 1 year. The 4-month follow-up only included women who answered at the 1-year follow-up

women with SUI. The outcome measures ICIQ-UI SF and PGI-I are validated and the ICIQ-UI SF is also highly recommended. The third outcome, sufficient treatment, is important from a clinical perspective and reflects the patient's goal of treatment, a recommended part of the composite end-points [22]. The possible predictors were chosen based on risk factors or findings from other studies [5, 6, 11, 12, 18-20, 23]. The percentage of women who underwent incontinence surgery during follow-up $(3.0 \%)$ was lower in our study than in other long-term studies (4.9-58 \%) [10]. We included all women who completed the follow-up, including the 5 who had undergone surgery. We also excluded these 5 women from the final analysis, with no effect on the results.

\section{Limitations}

A possible shortcoming of this study is the lack of an objective outcome measure for the amount or frequency of leakage. We chose to use patient-reported measures based on validated and highly recommended questionnaires. Patient-reported measures are important and correlate with reduced incontinence [24]. The losses to follow-up (32\%) are comparable with the upper range of other long-term studies on incontinence [10]. The women who did not complete the 1-year follow-up were younger and had more severe leakage than the women who completed the follow-up [13]. We do not expect the losses to follow-up to influence our results, because only the women who answered the 1-year follow-up were included in this study. The limited number of participants in this study may increase the risk of type II errors (false-negative), and there may be more predictors that we did not find. The large number of possible predictors that we analyzed could have created significant results by chance.

\section{Population and treatment}

The women in this study were generally highly educated and $75.7 \%$ had a post-secondary education, compared with $35 \%$ of women $\geq 16$ years of age in the general population of Sweden at the time of inclusion (i.e., 2009) [25]. In other fields, studies on online prevention efforts aimed at lifestyle changes have shown that participants are more often white, female, highly educated, and living in high-income countries [26]. This description fits our study population and may be problematic for generalizing the results because of the high education level. In short-term predictor studies, both higher [11] and lower [20] education have been described as predictors of a successful result. However, in our study, education was not a predictor in any of the logistic regression analyses. The NICE guidelines recommend 3 months of supervised PFMT as the first-line treatment for SUI [8]. However, Shamliyan et al. found no significant differences in treatment effects regarding continence rates or discontinuation between supervised PFMT and unsupervised PFMT [3]. The PFMT in this program is unsupervised, but, unlike studies that compare supervised and unsupervised PFMT [27, 28], the women in 


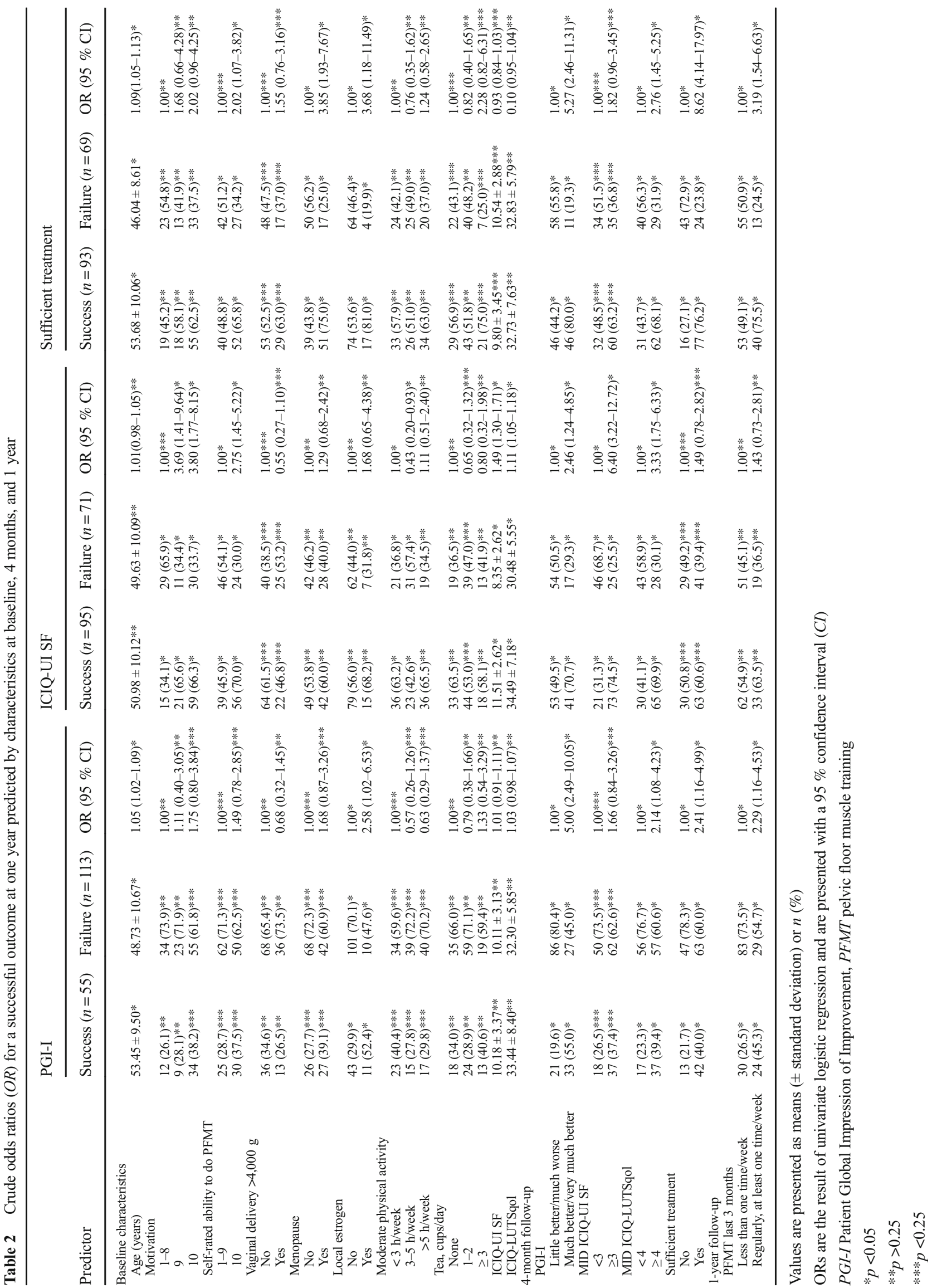


Table 3 Adjusted odds ratios (OR)* for a successful outcome at 1 year

\begin{tabular}{|c|c|c|}
\hline & OR $(95 \% \mathrm{CI})$ & $p$ value \\
\hline \multicolumn{3}{|l|}{ PGI-I } \\
\hline \multicolumn{3}{|c|}{ Predictive model (Nagelkerke $\mathrm{R}^{2} 0.30$ ) } \\
\hline Age (years) & $1.06(1.02-1.10)$ & $<0.001$ \\
\hline \multicolumn{3}{|l|}{ Moderate physical activity } \\
\hline$<3 \mathrm{~h} /$ week & 1.00 & \\
\hline $3-5 \mathrm{~h} /$ week & $0.37(0.14-0.93)$ & 0.04 \\
\hline$>5 \mathrm{~h} /$ week & $0.28(0.11-0.75)$ & 0.01 \\
\hline \multicolumn{3}{|l|}{ PGI-I, 4-month follow-up } \\
\hline Little better/much worse & 1.00 & \\
\hline Much better/very much better & $5.15(2.40-11.03)$ & $<0.001$ \\
\hline \multicolumn{3}{|c|}{ PFMT last 3 months, at 1 -year follow-up } \\
\hline Less than once a week & 1.00 & \\
\hline At least once per week & $2.32(1.04-5.20)$ & 0.04 \\
\hline \multicolumn{3}{|l|}{ ICIQ-UI SF } \\
\hline \multicolumn{3}{|c|}{ Predictive model (Nagelkerke $\mathrm{R}^{2} 0.51$ ) } \\
\hline ICIQ-UI SF, at baseline & $1.43(1.22-1.67)$ & $<0.001$ \\
\hline \multicolumn{3}{|l|}{ Self-rated ability to perform PFMT } \\
\hline $1-9$ & 1.00 & \\
\hline 10 & $3.04(1.31-7.08)$ & 0.01 \\
\hline \multicolumn{3}{|l|}{ Moderate physical activity } \\
\hline$<3 \mathrm{~h} /$ week & 1.00 & \\
\hline $3-5 \mathrm{~h} /$ week & $0.27(0.10-0.76)$ & 0.01 \\
\hline$>5 \mathrm{~h} /$ week & $1.02(0.38-2.76)$ & 0.97 \\
\hline \multicolumn{3}{|l|}{ MID ICIQ-UI SF, 4-month follow-up } \\
\hline$<3$ & 1.00 & \\
\hline$\geq 3$ & $6.85(2.83-16.58)$ & $<0.001$ \\
\hline \multicolumn{3}{|l|}{ Sufficient treatment } \\
\hline \multicolumn{3}{|c|}{ Predictive model (Nagelkerke $\mathrm{R}^{2} 0.45$ ) } \\
\hline Age (years) & $1.08(1.03-1.13)$ & $<0.001$ \\
\hline ICIQ-UI SF, at baseline & $0.86(0.75-0.98)$ & 0.03 \\
\hline \multicolumn{3}{|l|}{ PGI-I, 4-month follow-up } \\
\hline Little better/much worse & 1.00 & \\
\hline Much better/very much better & $3.05(1.18-7.84)$ & 0.02 \\
\hline \multicolumn{3}{|c|}{ Sufficient treatment, 4-month follow-up } \\
\hline No & 1.00 & \\
\hline Yes & $3.78(1.58-9.08)$ & $<0.001$ \\
\hline \multicolumn{3}{|c|}{ PFMT last 3 months at 1 -year follow-up } \\
\hline Less than 1 time/week & 1.00 & \\
\hline Regularly, at least 1 time /week & $2.99(1.23-7.27)$ & 0.02 \\
\hline
\end{tabular}

*Adjusted for age and predictors with a $p$ value $<0.25$ in the univariate logistic regression analysis

this study did not receive any face-to-face education by a physiotherapist during the program. Nonetheless, the women in our study population were significantly improved at 4 months, 1 year, and 2 years [13, 14].

\section{Outcomes and predictors}

We found that more severe incontinence was a factor that made women more likely to achieve success based on the ICIQ-UI SF, whereas the women with less severe incontinence were more likely to reach a successful result based on the outcome variable sufficient treatment. The literature on severity as a short-term predictor has reported inconsistent results, with some studies reporting that patients with a higher incontinence frequency have poorer outcomes $[11,18,20]$.
However, Hung et al. reported that women with more severe incontinence at baseline are more likely to be successful, based on self-reported results [12]. The choice of outcome variables seems to be very important when analyzing severity as a predictor. The three studies reporting poorer outcomes with more severe incontinence used objective measures, and the study that reported a more successful outcome with increased severity used a subjective outcome measure. When defining treatment outcomes for lower urinary tract symptoms (LUTS), Hilton and Robinson stated that it is important to acknowledge different perspectives. Subjective measures and quality of life were rated highly by the clinician, patient, and any "third party." Nevertheless, patients also found the objective measures cost reduction and avoidance of surgery important [22].

\section{Our findings in relation to other findings}

Our finding of a successful result at the 4-month follow-up being a predictor of long-term success is comparable with the results in a review on long-term results in which 7 out of 19 studies reported long-term outcome based on short-term success; the responders to the initial program maintained the result better than the non-responders [10]. The results after general resistance training seem to be maintained with one to two training episodes per week after previous involvement in training [29]. We found that regular PFMT at least once per week during the last 3 months at the 1-year followup more than doubled the OR of being successful at 1 year for sufficient treatment and PGI-I. Hung et al. found that increased pelvic floor muscle strength, but not PFMT adherence, was a predictor of success [12]. Furthermore, Theofrastous et al. described a reduction in incontinence episodes after PFMT, but the correlation between the improvement and PFMT was weak [23]. In contrast to short-term predictor studies, our results suggest that adherence to PFMT might be important for long-term success.

Our results indicate that increasing age is a predictor of success at the 1-year follow-up in women. No correlation has been found between age and outcome in other predictor studies (short-term) [11, 12, 18-20, 23]. Perhaps in the long-term, our outcomes benefit older patients with regard to more successful results. Younger women may be less accepting of incontinence and more likely to report being unsatisfied with the treatment, which corresponds well with the results of Labrie et al., who found that age $\leq 55$ years is a predictor of surgery after physiotherapy [30]. Another explanation may be that older women have more time to perform the PFMT. 


\section{Clinical implications}

More research and longer follow-ups are needed to further evaluate predictors of long-term success and develop specific recommendations for women with SUI. Even though no consensus is available on the optimal training routine, there are recommendations for short-term PFMT [8]. However, studies on training regimens for the maintenance of short-term results in the long term are still missing. Incontinence may affect the physical, psychological, and social well-being of affected individuals [3, 8, 9], but individuals are not equally affected [3]. Therefore, personalized advice would be helpful to provide high-quality treatment. Our results can contribute to predicting who will benefit from the PFMT and what can be done to increase the odds of achieving a successful outcome.

\section{Conclusion}

This study suggests that a successful result after 4 months, the performance of regular PFMT at 1 year, and older age are predictors of long-term success in women with clinically relevant SUI treated with a non-face-to-face training program based on PFMT. Our results can be helpful when informing patients with SUI about treatment based on PFMT in a clinical setting.

\begin{abstract}
Acknowledgements We would like to thank Susanne Johansson for the administration of the study. The study was supported by The Swedish Council for Working Life and Social Research, the Jämtland Country Council, and the Västerbotten Country Council (ALF).
\end{abstract}

\section{Compliance with ethical standards}

Conflicts of interest None.

Open Access This article is distributed under the terms of the Creative Commons Attribution 4.0 International License (http:// creativecommons.org/licenses/by/4.0/), which permits unrestricted use, distribution, and reproduction in any medium, provided you give appropriate credit to the original author(s) and the source, provide a link to the Creative Commons license, and indicate if changes were made.

\section{References}

1. Hannestad YS, Rortveit G, Sandvik H, Hunskaar S (2000) A community-based epidemiological survey of female urinary incontinence: the Norwegian EPINCONT study. Epidemiology of Incontinence in the County of Nord-Trondelag. J Clin Epidemiol 53:1150-1157

2. Haylen BT, de Ridder D, Freeman RM, Swift SE, Berghmans B et al (2010) An International Urogynecological Association (IUGA)/ International Continence Society (ICS) joint report on the terminology for female pelvic floor dysfunction. Int Urogynecol J 21:5-26
3. Shamliyan T, Wyman J, Kane RI. Nonsurgical treatments for urinary incontinence in adult women: diagnosis and comparative effectiveness (Internet). Rockville: Agency for Healthcare Research and Quality (US), 2012 (Comparative Effectiveness Reviews No. 36). Available at: http//www.ncbi.nlm.nih.gov/books/nbk92960/. Accessed February 2015

4. Huang AJ (2013) Nonsurgical treatments for urinary incontinence in women: summary of primary findings and conclusions. JAMA Intern Med 173:1463-1464

5. Hannestad YS, Rortveit G, Daltveit AK, Hunskaar S (2003) Are smoking and other lifestyle factors associated with female urinary incontinence? The Norwegian EPINCONT Study. BJOG 110:247254

6. Buckley BS, Lapitan MC, Epidemiology Committee of the Fourth International Consultation on Incontinence, Paris, 2008 (2010) Prevalence of urinary incontinence in men, women, and children-current evidence: findings of the Fourth International Consultation on Incontinence. Urology 76:265-270

7. Abrams P, Andersson KE, Birder L et al (2009) Recommendations of the International Scientific Committee: evaluation and treatment of urinary incontinence, pelvic organ prolapse and faecal incontinence. In: Abrams P, Cardozo L, Khoury S, Wein A (eds) Incontinence 4th International Consultation on Incontinence, Paris July 5-8, 2008, 4th edn. Health Publications, Paris, pp 1767-1820

8. National Institute for Health and Clinical Excellence. Urinary incontinence: the management of urinary incontinence in women. London, RCOG Press 2013; Available from: http://www.nice.org. uk/guidance/cg171. Accessed 10 September 2014

9. Dumoulin C, Hay-Smith EJ, Mac Habée-Séguin G (2014) Pelvic floor muscle training versus no treatment, or inactive control treatments, for urinary incontinence in women. Cochrane Database Syst Rev 5:CD005654. doi:10.1002/14651858.CD005654.pub3

10. Bø K, Hilde G (2013) Does it work in the long term?-A systematic review on pelvic floor muscle training for female stress urinary incontinence. Neurourol Urodyn 32:215-223

11. Schaffer J, Nager CW, Xiang F et al (2012) Predictors of success and satisfaction of nonsurgical therapy for stress urinary incontinence. Obstet Gynecol 120:91-97

12. Hung HC, Chih SY, Lin HH, Tsauo JY (2012) Exercise adherence to pelvic floor muscle strengthening is not a significant predictor of symptom reduction for women with urinary incontinence. Arch Phys Med Rehabil 93:1795-1800

13. Sjöström M, Umefjord G, Stenlund H, Carlbring P, Andersson G, Samuelsson E (2013) Internet-based treatment of stress urinary incontinence: a randomised controlled study with focus on pelvic floor muscle training. BJU Int 112:362-372

14. Sjöström M, Umefjord G, Stenlund H, Carlbring P, Andersson G, Samuelsson E (2015) Internet-based treatment of stress urinary incontinence: 1- and 2 years results of a randomised controlled trial with focus on pelvic floor muscle training. BJU Int 116:955-964

15. Yalcin I, Bump RC (2003) Validation of two global impression questionnaires for incontinence. Am J Obstet Gynecol 189:98-101

16. Avery K, Donovan J, Peters TJ et al (2004) ICIQ: A brief and robust measure for evaluating the symptoms and impact of urinary incontinence. Neurourol Urodyn 23:322-330

17. Nystrom E, Sjostrom M, Stenlund H, Samuelsson E (2015) ICIQ symptom and quality of life instruments measure clinically relevant improvements in women with stress urinary incontinence. Neurourol Urodyn 34:747-751

18. Cammu H, Van Nylen M, Blockeel C, Kaufman L, Amy JJ (2004) Who will benefit from pelvic floor muscle training for stress urinary incontinence? Am J Obstet Gynecol 191:1152-1157

19. Hendriks EJ, Kessels AG, de Vet HC, Bernards AT, de Bie RA (2010) Prognostic indicators of poor short-term outcome of physiotherapy intervention in women with stress urinary incontinence. Neurourol Urodyn 29:336-343 
20. Burgio KL, Goode PS, Locher JL, Richter HE, Roth DL, Wright KC et al (2003) Predictors of outcome in the behavioral treatment of urinary incontinence in women. Obstet Gynecol 102:940-947

21. Klovning A, Avery K, Sandvik H, Hunskaar S (2009) Comparison of two questionnaires for assessing the severity of urinary incontinence: The ICIQ-UI SF versus the incontinence severity index. Neurourol Urodyn 28:411-415

22. Hilton P, Robinson D (2011) Defining cure. Neurourol Urodyn 30: 741-745

23. Theofrastous JP, Wyman JF, Bump RC, McClish DK, Elser DM, Bland DR et al (2002) Effects of pelvic floor muscle training on strength and predictors of response in the treatment of urinary incontinence. Neurourol Urodyn 21:486-490

24. Burgio KL, Goode PS, Richter HE, Locher JL, Roth DL (2006) Global ratings of patient satisfaction and perceptions of improvement with treatment for urinary incontinence: validation of three global patient ratings. Neurourol Urodyn 25:411-417

25. Statistics Sweden. Yearbook of Educational Statistics 2015. Stockholm: Sweden; 2014 (updated 17 December 2014). Available at: http://www.scb.se/en_/Finding-statistics/Publishingcalendar/Show-detailed-information/?publobjid=22768. Accessed 29 January 2015
26. Kohl LF, Crutzen R, de Vries NK (2013) Online prevention aimed at lifestyle behaviors: a systematic review of reviews. J Med Internet Res 15:e146

27. Parkkinen A, Karjalainen E, Vartiainen M, Penttinen J (2004) Physiotherapy for female stress urinary incontinence: individual therapy at the outpatientclinic versus home-based pelvic floor training: a 5-year follow-up study.Neurourol Urodyn 23:643-648

28. Felicissimo MF, Carneiro MM, Saleme CS, Pinto RZ, da Fonseca AM, da Silva-FilhoAL (2010) Intensive supervised versus unsupervised pelvic floor muscle training for thetreatment of stress urinary incontinence: a randomized comparative trial. Int UrogynecolJ 21: $835-840$

29. Kraemer WJ, Adams K, Cafarelli E, Dudley GA, Dooly C, Feigenbaum MS et al (2002) American College of Sports Medicine position stand. Progression models in resistancetraining for healthy adults. Med Sci Sports Exerc 34:364-380

30. Labrie J, Lagro-Janssen AL, Fischer K, Berghmans LC, van der Vaart CH (2015) Predicting who will undergo surgery after physiotherapy for female stress urinary incontinence. Int Urogynecol J 26:329-334 